\title{
A CONCEPT OF INFORMATION SYSTEM IMPLEMENTATION (CRM AND ERP) WITHIN INDUSTRY 4.0
}

\author{
Željko Stojkić, Ivica Veža, Igor Bošnjak \\ University of Mostar, Hrvatskih velikana br.1, Mostar 88000, Bosnia and Herzegovina \\ University of Split, R. Boškovića bb, Split 21000, Croatia
}

\begin{abstract}
In this paper the concepts of information system implementation (ERP and CRM) will be presented according to the recommendations of Industry 4.0. In the first chapter of the paper, definition of Industry 4.0 with its characteristics and description of INSENT project with its aims will be given. The result of the first phase of the project is presented with emphasis on using and benefits of information technologies. According to results of the first phase of the INSENT project, the outcome is that it is necessary to develop a new concept of ERP and CRM system implementation. It is realized that the Industry 4.0 model cannot be directly implemented in Croatian and $\mathrm{BiH}$ industry. In the next chapter, the theoretical concept of ERP/CRM system introduction is given. After that, the role of ERP/CRM systems in achieving Industry 4.0 is described. In the conclusion, the future steps of work are going to be presented as one step for achieving Industry 4.0.
\end{abstract}

Keywords Industry 4.0; ERP; CRM; Lean management;Cyber Physical Systems
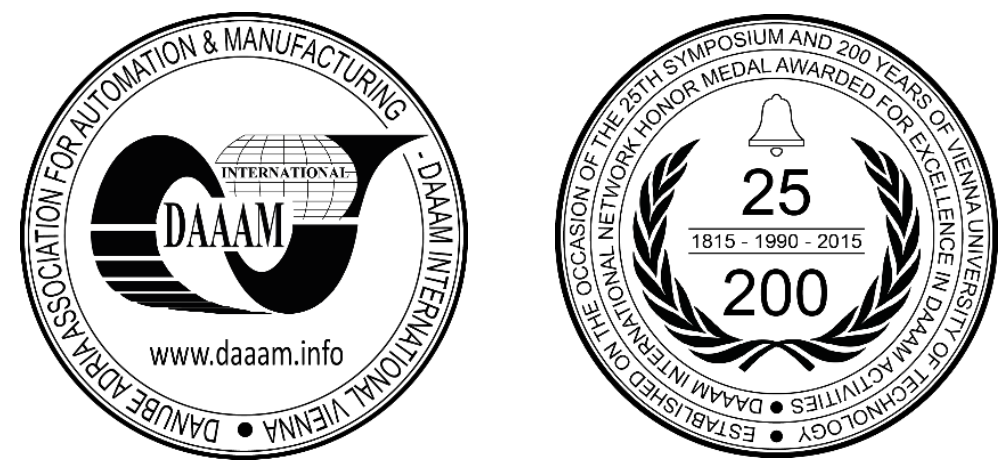

This Publication has to be referred as: Stojkic, Z[eljko]; Veza, I[vica] \& Bosnjak, I[gor] (2016). A Concept of Information System Implementation (CRM and ERP) within Industry 4.0, Proceedings of the 26th DAAAM International Symposium, pp.0912-0919, B. Katalinic (Ed.), Published by DAAAM International, ISBN 978-3-902734-07-5, ISSN 1726-9679, Vienna, Austria

DOI: $10.2507 / 26$ th.daaam.proceedings. 127 


\section{Industry 4.0 and INSENT project}

The first three industrial revolutions are the outcome of introduction of machines, electricity and information technology. Now, introduction of the Internet "of things and services" in manufacturing starts the fourth industrial revolution: Industry 4.0. This type of industry is based on a Smart enterprise model. In the last two hundred years the economy development has followed 3 industrial revolutions (Figure 1).

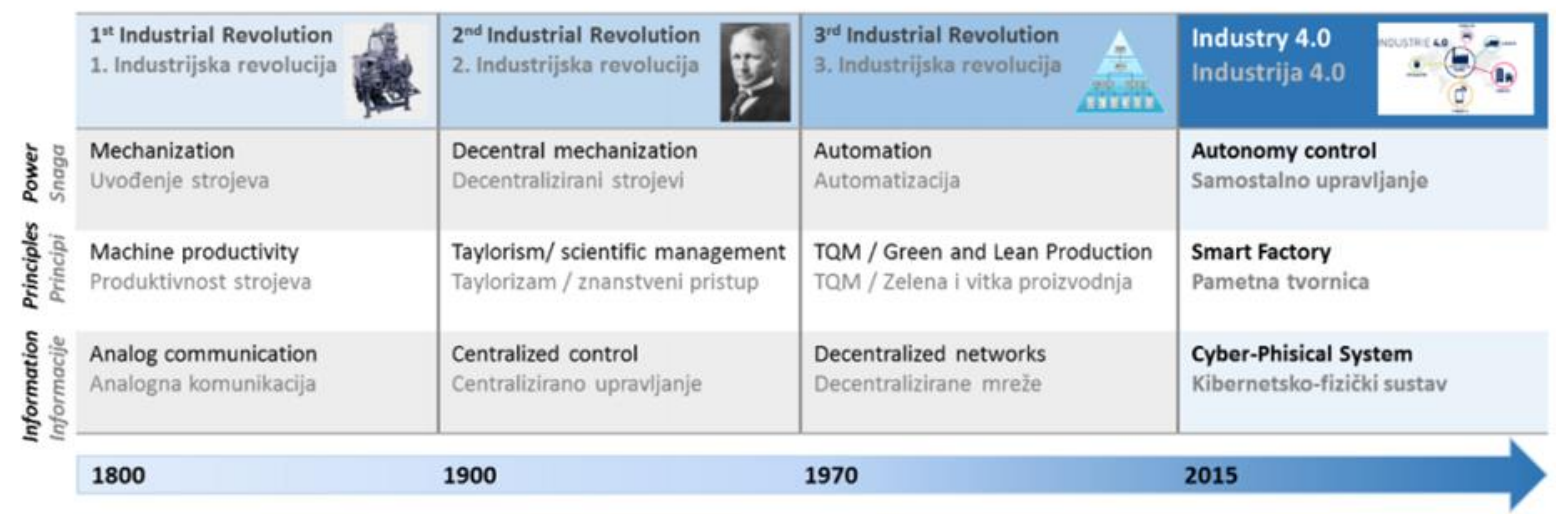

Fig. 1. Development of industrial revolutions

The embedded manufacturing systems are vertically networked with business processes of other companies and horizontally connected with spatially dispersed networks that add value. Smart enterprises enable fulfilling of customer's wishes so it is possible for a single piece production to be profitable. At Industry 4.0, the dynamic business and engineering processes enable changes in production "in the last moment" while having a possibility, for example, to be flexible when it comes to distortions and errors made by a supplier.

So, basic characteristics of Smart enterprise may be summarized in the below-listed items:

- Smart personalized product - requires flexibility and high level of ICT integration in manufacturing;

- Manufacturer and service provider - extended product supply: product and service being integrated in one, or being a manufacturing service provider;

- High cooperation level - requires a high level of ICT integration to enable a common product development and cooperative manufacturing.

According to Roland Berger's research, Croatia and BiH have a very low index of Industry 4.0 readiness and they belong to the "'hesitators" country group (Figure 2). It means that it is necessary to develop a new strategy that would raise Croatian and $\mathrm{BiH}$ Industry 4.0 readiness index.

A research group, made of scientists from the Faculty of Electrical Engineering, Mechanical Engineering and Naval Architecture ("FESB") and Faculty of Economics (EFST) of the University of Split as well as from the Faculty of Mechanical Engineering and Computing ("FSR") of the University of Mostar, is working within the INSENT project (Innovative Smart Enterprise) on a four-year scientific and research project of smart and innovative enterprise development, financed by Croatian Science Foundation. The main goal of the project is to develop Croatian model of Innovative Smart Enterprise.

In previous research, analysis of the problems of implementation of information systems in $\mathrm{BiH}$ was done, and the results thereof serve as a basis for further research and recommendations for implementation of information systems in companies that are in the target group of INSENT project.

Within the Work package 1 Analysis of current state of Croatian and BIH industrial companies the research has been done to determine a current situation of Croatian industrial companies. That has been done through questionnaires and interviews with managers in companies. The aim of this research was to collect the information from as many companies as possible. After that, the analysis of the situation of Croatian industrial companies is done.

In order to analyze the current state of Croatian industrial enterprises, the questionnaire is defined, set on the Web and sent to e-mail address of 1,936 Croatian companies, which were able to, simply, over the Internet, respond the questions. It was responded by 161 companies, which corresponds to a sample of $8 \% .79 \%$ companies stated their names, and $21 \%$ remained anonymous.

For the assessment of the representativeness of the sample, the data obtained have been analyzed according to adopted Croatian hierarchically structured Nomenclature of Industrial Products (and services) NIP, version 2013. It is designed to measure the annual industrial production in physical quantities (volume) and values. It can be concluded that a representative sample is obtained, because the data obtained from the questionnaire and Biznet.hr are not significantly different. 
At the beginning of the research, the fundamental question was made: How to determine the level of industry in Croatian companies with respect to the industrial revolution? Based on the conclusions of the workshop it was decided to issue instructions to companies that would monitor the activities of the business process from product development, planning and management, production to quality assurance.

As the area of interest of this study, the main task, for our group, was to focus on results related to the level of development of enterprise in the field of information systems. The aim of this paper is, based on the results of the first package of INSENT project, as presented in the next section, with an emphasis on information systems, to show the possible directions of implementation of ERP / CRM systems for companies in Croatia and Bosnia and Herzegovina within the Industry 4.0 .

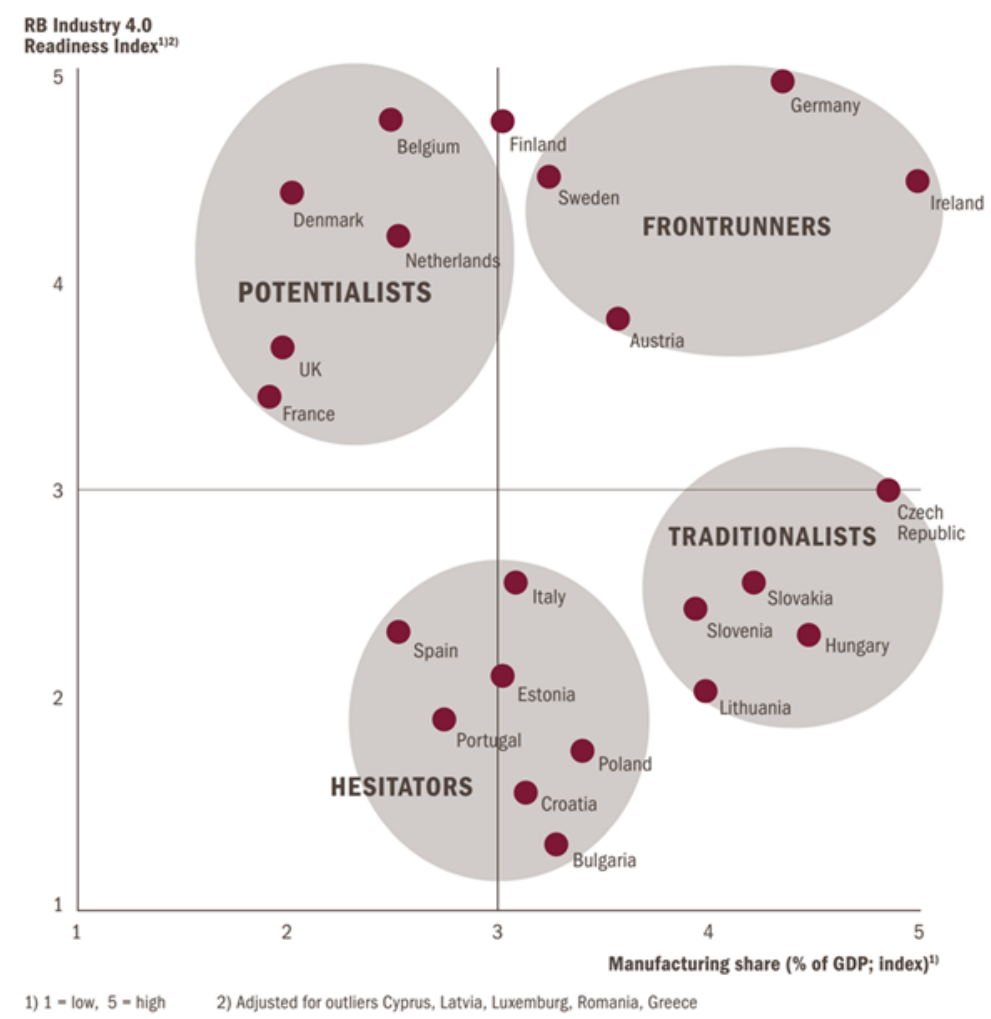

Fig. 2. Relation between industry share in BDP and readiness of European countries for introduction of Industry 4.0

\section{Results of the Analysis of current situation of Croatian and BiH industrial companies}

The situation of an ICT application in analyzed industrial companies could be summarized in the following items:

- $\quad$ Business processes and PLM/ERP systems

PLM and ERP systems need to be a support for business processes which manage material and product flow through the whole company and during the whole life cycle. However, during detailed analysis of the companies it is concluded that there is no good standardized business practice for managing different types of articles in information systems - repro material, semi-finished product, product, basic means, .. - and in practice there is a need for higher level of accountingrelated knowledge and better ERP/CRM solutions.

- (Non) Integration of information solutions

One of the problems in business monitoring represents the necessity for entering the items into multiple systems. Namely, in some parts of companies the integration of systems/solutions is not performed well (e.g. through XML or EDI standards), but the articles are being entered manually into multiple systems with the same names and codes. A common example of (mostly good) integration on the level of the article is the integration of accounting-related solutions of domestic companies/agencies with ERP solutions of foreign companies. The common example of business process that has a non-integrated solution is the process of quality management.

- Integration of ERP and CAD systems

The incoherence between the processes of design and manufacturing is also transmitted on IT level: there are few companies where a direct electronic communication is accomplished between the CAD and ERP solutions.

- E-business

Exchange of documents with partners over the Internet is based mostly on inquiries, offers, price lists and orders in PDF and XLS format via e-mail, while the direct exchange of documents between the information systems (document exchange 
by XML and EDI standards) is very rare. This low level of readiness for e-business is a direct outcome of the abovementioned characteristics.

\section{- Cloud business}

The owners of business processes in companies are aware of principal advantages (lower costs of equipment and maintenance, improvement in functionality of SW and business in general,) and risks (security and protection of data). Almost all of them use mail services in one public cloud, while in operations a lot of companies, in addition to the classic solutions, use (on premise) the cloud solutions (on-demand) in some form of private cloud. Regarding the business applications that are located in clouds, it is necessary to note that they are mostly old applications which are hosted on a local server or on a remote server. We have not seen a business application based on cloud architecture. However, it should be pointed out that such architecture ensures two basic requirements of manufacturing companies: business continuity and security and protection of data.

- Integration of systems on MES level (Manufacturing Execution System)

A direct communication of ERP systems and machines in a production plant is on very low level (plan-order-evidencereports). Even in the companies that monitor the production plant in details and where the machines are equipped with software for monitoring individual operations, the specialized software is not integrated with the planning software (ERP or other specialized software). So, in plants a common manual evidence of individual operations is made, and consequently it is harder to report on and monitor the plant production

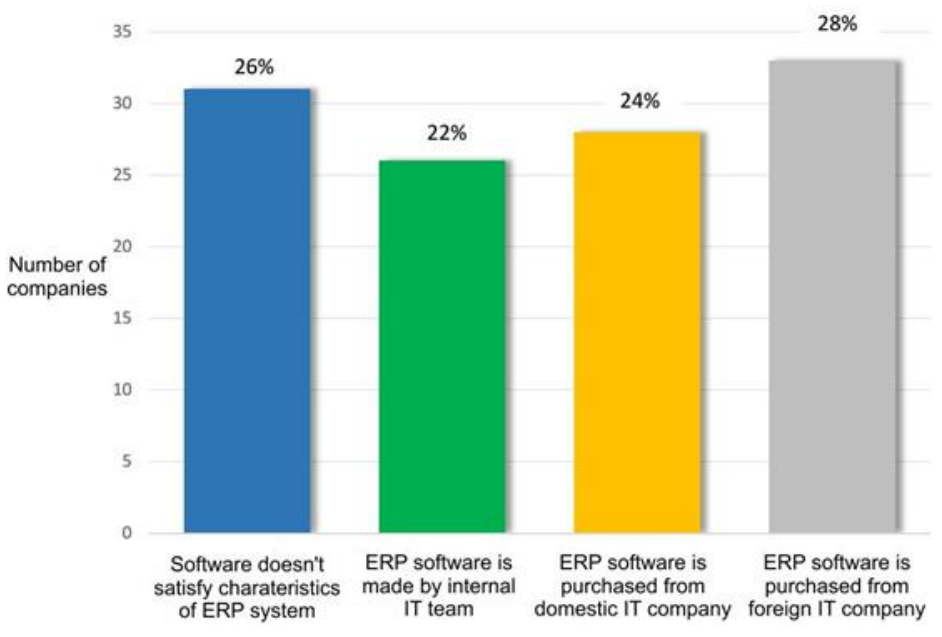

Fig. 3. Questions and answers about ERP system

\section{Integrated information systems}

ERP stands for "Enterprise Resource Planning". The term ERP system means the general standard integrated business and economic software. With this software it is possible to perform a variety of business and economic activities (financial, manufacturing, logistics...) with the support of information technology.

CRM (Customer Relationship Management) may be defined as a strategy of management and communication with customers aimed at collecting information about customer that are used for increasing customer satisfaction and loyalty, in order to have better, longer and more profitable relationship with them.

\subsection{Implementation of an integrated information system in companies}

Implementation of an integrated information system in companies presents a very significant project for the company. Such a project is not only a significant engagement of resources, necessary for business, but also a significant risk to the economic success of the project. For this reason it is necessary to pay special attention to the planning of these projects.

The first thing to start with is to choose the strategy for implementation of the project. Basically, there are two possible strategies for implementation:

- phasing,

- Simultaneous introduction.

Beside the choice of strategy and standard success factors of the project, the outcome of the project is significantly affected by the following:

- $\quad$ Type of the chosen programme solution in terms of

○ functionality of the programme solution,

- reputation of the manufacturer of the programme solution,

- reliability of the programme solution,

○ use of reference models, 
○ technological completion and modernity

- adjustment of the solution to the business practice,

- $\quad$ - Project contractor in terms of

$\circ$ experience in programme solutions introduction,

- partnership between the company and the provider (contractor),

- customer confidence in the ability of the project constructor,

- Company which is introducing the new IS in terms of

○ support from top management,

○ compliance of IT and projects with strategy of the company,

○ wide support for the project,

- transparency of data and procedures in the organization,

- levels of the information technology and information knowledge within the company,

○ use of modern forms of communication and team work,

- knowledge of project management techniques

○ quality of users' skills,

- project duration.

The concept of implementation describes and generally regulates the entire process from initiation through implementation to completion of the project. Given that there are various kinds of information system implementation projects, there are many implementation concepts described in the literature. From classic waterfall model or spiral model to the individual implementation concepts offered by the manufacturer of standard ERP/CRM systems.

Integrating ERP and CRM systems could be particular difficult since it involves not only the local firm itself but also their customers. As the firm develops a new IT infrastructure it develops rules and procedures that goes beyond the firm boundaries. The new business process that are supported by ERP integrated with CRM systems are like dominoes in a row. That is, each new transaction sets of a cascade of new events. As example - a marketing campaign generate a new sales order which triggers inventory levels, production order, purchase order, quality orders, invoices, etc. New processes that are valuable for firms to pursuit [9]

\subsection{Concept of implementation of information systems}

Implementation of information system is done in two parts.

1. Implementation of the system in the entire company, achieving the basic functionality of the system.

2. System implementation from the achieved level in the first part of the implementation to the desired level by using tools to improve the business process.

The first part includes the implementation of the system in the entire company through two forms of problem describing. One form defines the phases of introduction of the new information system in the company, while the other form defines the organizational reference model of the company which is adjusted to the individual needs of the process of that company. This part of information system introduction is divided into five steps:

1. Project management

2. Analysis of the existing situation

3. Concept development that meets the needs of the company

a. Reference models

b. Models within the ERP/CRM system

4. Installation of the information system

5. IS implementation

The first step - project management is carried out to define the objectives, to make a project plan, to form the project team and to do other activities necessary for realization and implementation of the project.

The second step - analysis of the existing situation includes the procedure of interviewing and documenting the process flows and defining the specific values of measured quantities, which will be further processed through the analysis of the bottleneck in the process.

In the third step (concept development that meets the needs of the company) the analyzed processes are discussed among the project team and a decision is made about the changes that need to take place. Within the third step, 'concept development", the reference models is developed. On one hand, these models can be adjusted to the functionality of the software package and its module. On the other hand, these reference models offer a transparent view of business processes that can be adapted to the individual needs of the company and simultaneously they may serve as a basis for adapting the software to the needs of the company. Another way is to adapt the existing business processes to the business processes defined within the standard software solution. Namely, inside the majority of the standard ERP/CRM systems a big part of standard business processes has been integrated with variations which are specific to the individual industry. This 
characteristic of the ERP/CRM system presents the potential of knowledge embedded in the standard ERP/CRM system which can be used in the information system implementation.

Parameters of the information system are edited or adjusted in the fourth step.

The last, fifth step, is performed to implement the software and to do the systemic and organizational documenting. In the implementation it is necessary to pay attention to the order of completion of planned steps to obtain the results of a new information system introduction very quickly. Return on investment has a high priority in this stage. The first part in this fifth step (IS implementation), in addition to the basic ones that are linked to the master data, is a warehouse management and processing of orders for suppliers, processing of customer orders and processing of production orders. It is necessary to fully complete this part of implementation. The second part is necessary as to optimize the execution of tasks within a particular department. In the third part of the implementation it is necessary to realize the functions provided by the software package referring to the statistics, reports and other variables that occur as a result of working with a software package. Standard port ARIS-Tool set enables transfer of the concept developed with this tool into MS-Project which than enables project plan forming with necessary resources and implementation terms of each activity.

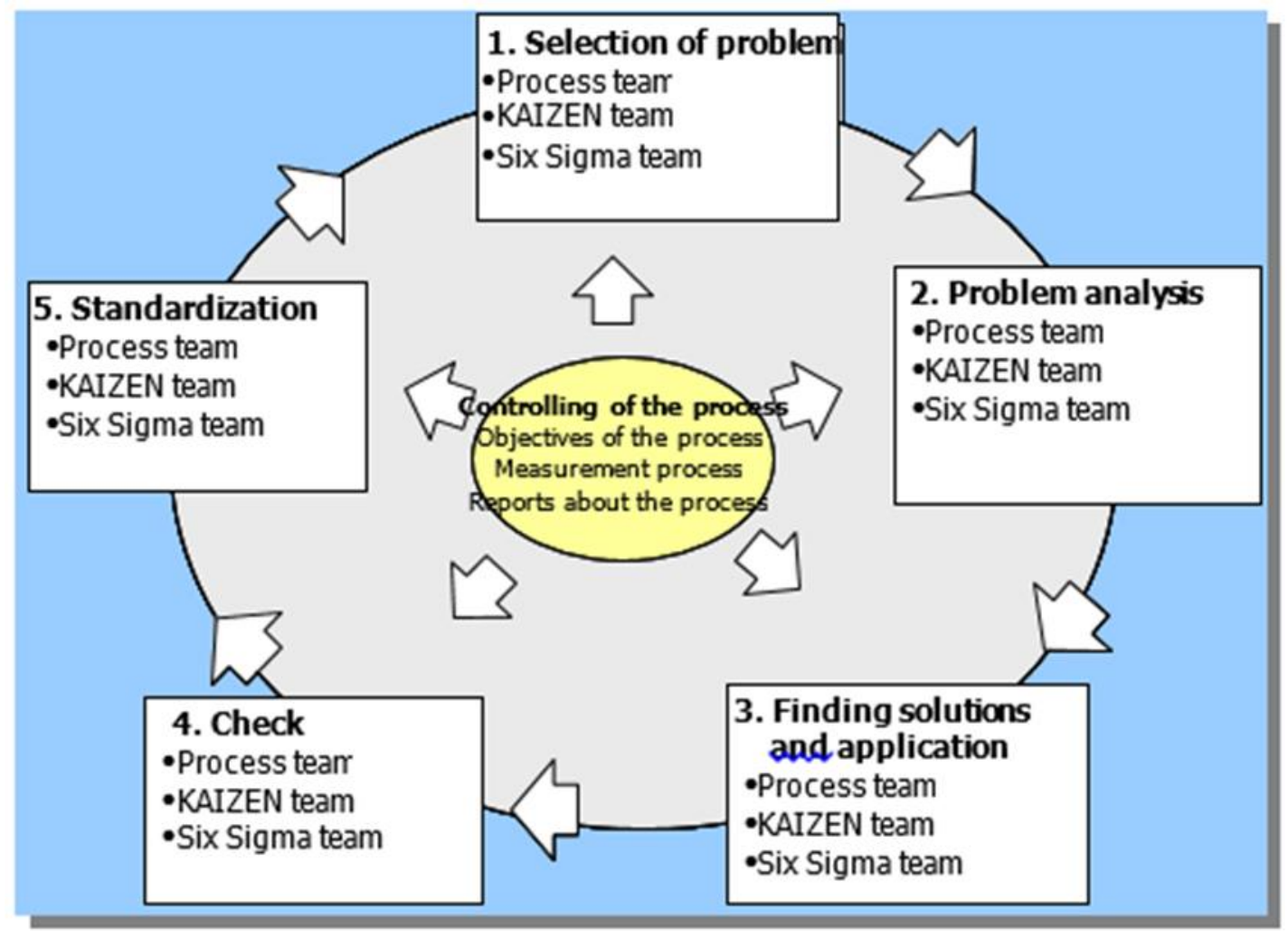

Fig. 4. The second phase of the information system implementation

After the first phase of the information system implementation, it is necessary to move to another part of the implementation by using standard tools for business process improvement Figure 4 (Total Cycle time, KAIZEN, Value stream mapping, Six Sigma). Employees of the company are highly engaged in this part of the information system implementation with a minimum involvement of the consultants or programmers. More effects occur during the second step of the information system implementation and simultaneous application of the methods for business process improvement.

The goal of proposed concept is that, from the beginning of the project, the company, which is introducing the new information system, has an insight into costs, duration and progress of the project. In addition, the company can use the moment of the information system implementation to change and improve the business processes and to continuously improve the process. This concept makes the introduction of the new information system more transparent and clear, and it is possible to control and achieve the objective of the project. This implementation concept allows parallel improvement of business processes of the companies and business process automation through implementation of integrated information systems. [4]

\subsection{Role of ERP/CRM systems in achieving Industry 4.0}

For today's enterprises, ERP is a basic system that runs the job. None of the companies could function without the ERP / CRM systems. But on the way to the production of the future with the existing ERP / CRM systems, there are 
huge barriers. ERP / CRM systems will continue to be the backbone of the company, but the existing ERP / CRM solutions need to be developed from the ground up into ERP / CRM systems of the next generation.

ERP / CRM systems of the next generation will have the following characteristics:

- Create an environment for decision-making. Functionality of the new ERP / CRM solutions should provide information to end users via tablet computers and mobile phones. These benefits and improvements will increase productivity and help the employees to fully use the power of ERP / CRM systems.

- Built-in Big data analytics technology should allow an automated analysis of large amounts of unstructured and different kinds of information, gathered in real time from business processes.

- To provide functionality as a virtual application that will allow enterprises and their partners to do business in real time through an intelligent value chain.

- Integration with social networks to facilitate the faster forwarding of information to end users. [5]

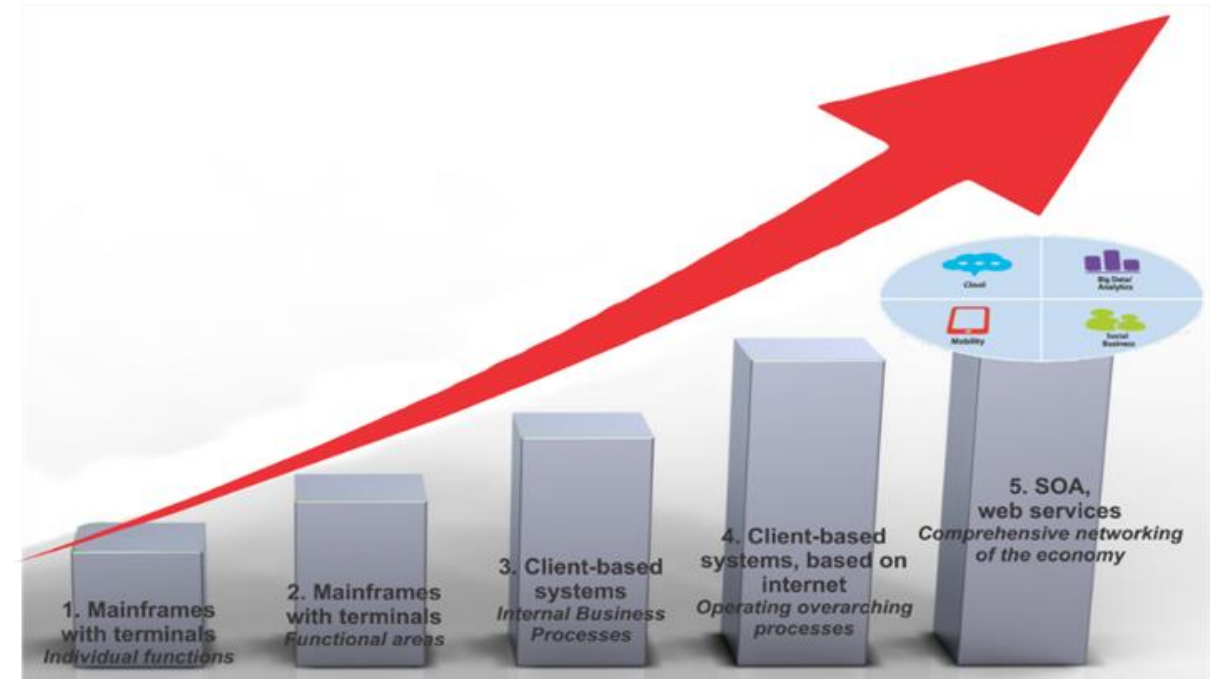

Fig. 5. Development of ERP systems

\section{Conclusion}

The road to the manufacturing industry of the future will require today's enterprises to undertake a thorough transformation of their business models. According to the research, conducted on the project INSENT, an industrial maturity of Croatian companies is 2.15 , which is very low. Considering that the questionnaire was responded by large number of companies that are in Republic of Croatia at the highest level of industrial maturity, it can be concluded that the average maturity of the Company is less than the stated 2.15. A detailed analysis of the selected companies showed that the companies were aware of their basic weakness: employees cannot follow the progress of technology and organization, and their lag is even bigger than it is considered by the analyzed companies. But, on the other hand, while taking into account that there are rare companies whose employees spend more than 5 days per year at training, and that 95\% of the companies does not have a systematically solved retraining of employees, it can be concluded that the companies currently do not work enough on development and advanced training of their employees. In this paper, the aim was to highlight the importance of ERP / CRM system on the road to industry 4.0 achievement as well as the concepts of implementation of these systems in the enterprise. The results will be further discussed in future researches within INSENT project, so the goal is to make a detailed analysis of degree of development of ERP / CRM systems in companies and to make recommendations for implementation and further development of ERP / CRM solutions taking into account the specific features and degree of enterprises in Croatia development.

\section{Acknowledgements}

This work has been fully supported by Croatian Science Foundation under the project 1353 Innovative Smart Enterprise (INSENT).

\section{References}

[1] Veža I. et al., Project Report for Work Package 1 (WP 1): "Analysis of the current state of Croatian industrial enterprises", Faculty of Electrical Engineering, Mechanical Engineering and Naval Architecture (FESB), University of Split, Split 2015.

[2] WHATIS, Definition of thousands most current IT-relevant words, http://whatis.techtarget.com/

[3] Milović B., Differences crm and e-crm business strategy, Infoteh-Jahorina Vol. 10, Ref. E-IV-15, 2011, p. 720-724, 
[4] Stojkić Ž., Majstorović I., Improving business organisation through the implementation of integrated IS, 23rd International DAAAM Symposium, Volume 23, No.1, ISSN 2304-1382, Wien, 2015.

[5] Manenti P., Veronesi L., Lee W., The Future of Manufacturing, IDC Manufacturing Insights, 2014.

[6] Martens P.,Integrierte Informationsverarbeitung 1, Gabler Verlag, ISBN 978-3-8349-1645-7, Wiesbaden, 2009.

[7] Z. Stojkic, V. Majstorovic, V. Višekruna, Application of Lean tools and xRM software solutions in order to increase the efficiency of business processes, Procedia Engineering Volume 69, 2014, Pages 41-48

[8] EL Sawy, Redesigning enterprise processes for e-Business, McGrow- Hill, 1993.

[9] Ruivo P., Mestre A., Johannsonb B. et. al., Defining the ERP and CRM Integrative Value, Procedia Technology Volume 16, 2014, Pages 704-709 